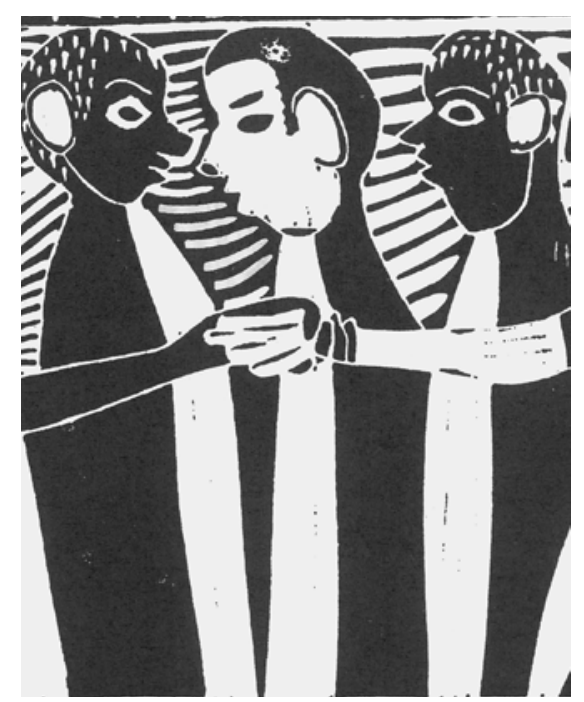

\title{
DEMOCRACY AS A COMMUNITY OF LIFE
}

\author{
Achille Mbembe
}

\section{Preliminary observations}

During the last quarter of the twentieth century we have witnessed the development of modes of ethical reasoning which dealt with the difficult question: what is 'the human' - or what remains of 'the human' or even of 'humanism' - in an age of violence, fear and torture; war, terror and vulnerability. Propelled by the repetition of violent events and human-made catastrophes and disasters, this critique has profoundly shifted the manner in which we used to define law and life, sovereignty and the political. It is now understood that if life itself has become the prime medium for exerting power, power in turn is fundamentally the capacity to control and redistribute the means of human survival and ecological sustainability.

Some of these forms of political and cultural critique are not simply paying incidental attention to the religious. In most instances, they have explicitly and deliberately engaged with theology itself. A number of secular intellectuals have moved beyond a time, not so long ago, when generation after generation of leftist revolutionaries 
denounced religion as a force of alienation which threatened human freedom. To a large extent, this new critique has also taken the form of witnessing. As has long been the case in black radical intellectual traditions, to witness is the attempt to disrupt and destabilise the prevalent order of things. The task of the witness is to reopen the emancipatory possibilities which, as a consequence of the structured blindness and collective self-deception of the age, are in danger of foreclosing the future. Propelled by the belief that history can be made possible again, late 20thcentury forms of critique have posited the pursuit of truth as a form of struggle in and of itself. Furthermore, the turn to the politico-theological has been the cornerstone of a renewed drive to expand our definition of "the human" and to re-imagine democracy as a community of life - life itself understood as a relentlessly regenerative force and possibility.

The emergence of late 20th-century forms of theologico-political critique has coincided with our disjointed world experiencing a radical uncertainty. This sense of uncertainty particularly affects three domains of social life: (1) the nature of historical praxis; (2) the categorical foundations of experience; (3) and the moral economies of signification. We no longer have ready-made answers to such fundamental questions as: Who am I? Who is my neighbour? What should we do with our (former) enemies? How should we treat the migrant, the asylum seeker, the stranger or the prisoner, the widow and the orphan? Can we forgive the unforgivable? What is the relationship between the quality of persons on the one hand and material wealth, poverty, hunger and disease on the other? Is there anything that can be considered to be so priceless as to be immune from sacrifice? If the possibilities of utopian thinking have receded, what are the conditions of a radical, future-oriented politics in this world and in these times?

Africa is a particularly revealing site from which to reframe these renewed interrogations of 'the human', of 'life' and of 'possibility'. Here, under conditions of slavery, colonisation and apartheid, brutal forms of dehumanisation have raised, in the starkest terms possible, the political and moral dilemmas of human difference. A racially exclusive ideological discourse in the heyday of conquest and occupation, 'humanism' was predicated on the belief that a difference of colour was a difference of species. Race in particular did not simply become a crucial, pervasive dimension of colonial domination and capitalist exploitation. Turned into law, it was also used as a privileged mechanism for turning black life into waste - a race doomed to wretchedness, degradation, abjection and servitude.

This is why, in their effort to vindicate their race, black intellectuals devoted most of their energies drawing complex portraits of themselves as actors in the history of humankind. As a result, two perspectives have historically dominated modern African discourses on 'the human'. The first - a substantivist perspective that used blackness as a strategic concept in a broader economy of self-affirmation and reinvention - ended up giving priority to an ontology of difference. To the colonial negation of black humanity, it substituted a narrative of black collective identity born of a common historical experience of subjugation and suffering. But even in the most radical forms of black self-assertion, race consciousness was always a transitional 
move on the way to universal or planetary humanism. Although always keen to provide a full account of 'the lived experience of the black' (Fanon), the second a political and future-oriented perspective - sought to move away from racialism and toward seeing each human being as only a human being in a future shared community. Such a community was usually envisaged as a community of life, freedom and possibility. It included everyone equally and was produced through struggle.

Today, questions concerning the place of race in capitalism and capitalism's intrinsic capacity to generate 'the human' as waste are being raised anew, at a time when radical shifts can be observed in the way neo-liberalism operates. In many places, the Continent is witnessing the consolidation of rapacious and predatory modes of wealth extraction. As Jean Comaroff writes, a new scramble for Africa is underway. Many of the investments currently being made flirt with forms of deregulation that pave the way for criminal economic transactions - trade in blood diamonds, contraband substances, protected species, sex workers, toxic dumping. Privatisation is being carried out in the midst of acute levels of material deprivation. Both the logic of privatisation and that of extraction are underpinned and buttressed by various processes of militarisation. In order to raise profitability levels, capital and power manufacture wars and disasters, feeding off situations of extremity which then allow for 'indirect forms of private government' of which 'humanitarian interventions' are but the most visible. Where access to wage labor is still a - remote - possibility, it is more and more embedded in a logic of disposability.

\section{The 'human' in the South African context}

Whether there is anything which is still to be rediscovered or to be reanimated from the term 'the human' takes on a paradoxical resonance in contemporary South Africa. With the end of apartheid, South African culture and society was confronted with the urgency of engaging in affirmative politics in lieu of the politics of destruction of the years of racial segregation. Affirmative politics entailed the production of social horizons of hope. At the same time, it meant resisting both the inertia of the present and the nostalgia of the past. To reconstruct what centuries of racial brutality had destroyed, a balance had to be found between the mobilisation, actualisation and deployment of cognitive, affective and creative possibilities which had not so far been activated, along with a necessary dose of oppositional consciousness.

Critical humanism in this new context would have meant a persistent commitment to the possibilities and powers of life. There is substantial evidence that a return to the question of the possibilities and powers of life as a precondition for the reconstitution of 'the human' in politics and culture was recognised as a matter of ethical and political urgency during the first decade of democracy. During this decade, South Africa became a model of how to dismantle a racial mode of rule, strike down race-based frameworks of citizenship and the law while striving to create racial equality through positive State action. The post-apartheid State fostered a normative project with the aim of achieving justice through reconciliation, equality through economic redress, democracy through the transformation of the law and the restoration of a variety of rights, including the right to a dignified life. This normative project was enshrined 
in a utopian Constitution that attempts to establish a new relationship between law and society on the one hand and law and life on the other, while equating democracy and the political itself with the ethical and the just. This Constitution's underlying principle is ubuntu or human mutuality. It promises a transcendence of the old politics of racial difference and an affirmation of a shared humanity. Underpinning the Constitution is the hope that, after centuries of attempts by white power to contain blacks, South Africa could become the speech-act of a certain way of beingin-common rather than side by side.

This drive to 're-humanise' society and culture and to institutionalise a new political community that defines itself as an ethical community is nevertheless unfolding against various odds. Perhaps to a degree hardly achieved in the rest of the Continent, the human has consistently taken on the form of waste within the peculiar trajectory race and capitalism espoused in South Africa. Traditionally, we speak of 'waste' as something produced bodily or socially by humans. In this sense, 'waste' is that which is other than the human. Traditionally, too, we speak of the intrinsic capacity of capitalism to waste human lives. We speak of how workers are wasted under capitalism in comparable fashion to natural resources. Marx in particular characterises capitalist production as thoroughly wasteful with what he calls 'human material' just as it is with 'material resources'. It squanders 'human beings, living labour', 'squandering not only flesh and blood, but nerves and brain, life and health as well', he writes. In order to grasp the particular drama of the human in the history of South Africa, we should broaden this traditional definition of 'waste' and consider the human itself as a waste product at the interface of race and capitalism. Squandering and wasting black lives has been an intrinsic part of the logic of capitalism, especially in those contexts in which race is central to the simultaneous production of wealth and of superfluous people.

Today, this logic of waste is particularly dramatised by the dilemmas of unemployment and disposability, survival and subsistence, and the expansion in every arena of everyday life of spaces of vulnerability. Despite the emergence of a solid black middle class, a rising superfluous population is becoming a permanent fixture of the South African social landscape with little possibility of ever being exploited by capital. Only a dwindling number of individuals can now claim to be workers in the traditional sense of the term. How to govern the poor has therefore become one of the biggest moral questions facing the nascent democracy. Behind policy debates on 'welfare' and 'service delivery' loom fundamental ethical choices that will determine the nature of the South African experiment in democracy - questions of how to right historical wrongs; what is the relationship between personal or collective injury and larger problems of equality, justice and the law; hunger and morality; owning and sharing; or even truth, hope and reconciliation. The urgency of these new moral dilemmas is such that, for the democratic project to have any future at all, it should necessarily take the form of a conscious attempt to retrieve life and 'the human' from a history of waste. 


\section{Wealth and property}

Meanwhile, wealth and property have acquired a new salience in public debate. They have become the key, central idioms to framing and naming ongoing social struggles - from imagining the relationship between 'the good life' to redefining value itself; from claims of citizenship, rights and entitlements to the definition of the forms of property and the economy itself (whether we should nationalise or not); from matters of morality to those of lifestyle and accountability.

The centrality of wealth in the moral discourse concerning the 'human' is not new. In various parts of pre-colonial Africa, discourses on 'the human', or, on 'humanity' almost always took the shape and content of discourses about 'wealth', 'personhood' and 'social multiplicity'. Traditional definitions of wealth usually encompassed 'people', 'things' and 'knowledge'.

'People', that is, other human beings, were not only the most important unit of measurement of ultimate value. They also formed the material basis or infrastructure of human life. 'People' consisted of interpersonal dependents of all kinds - wives, children, clients and slaves. As Jane Guyer argues in a striking study of forms of wealth in pre-colonial Equatorial Africa, they were sought, valued, and at times paid for at considerable expense in material terms. Kinship and marriage especially were critical components of accumulative strategies. But wealth also covered traded goods, including the imported goods brought from elsewhere. Things could be personalised objects. Goods could be functionally interchangeable with human beings who in turn could in certain respects be 'objectified' or converted into clients or followers.

Wealth - embodied in rights in people - remained a persistent principle of African social and moral life even in the midst of the various shifts induced by the slave trade and colonialism. Knowledge on the other hand was understood as an ever shifting spectrum of possibility. Jane Guyer makes it clear that it was highly valued, complexly organised and plural by definition. There was no social organisation of kinship and material life that did not depend, to some extent, on a regime of distribution of knowledge - the arts, music, dance, rhetoric, spiritual life, hunting, gathering, fishing, cultivation, wood-carving, metallurgy. If certain forms of knowledge were specialised, controlled and monopolised by a small cadre of experts or a secret society hierarchy, other forms of knowledge were conceptualised as an open and unbounded repertoire. This unboundedness made it possible for such forms of knowledge to be widely distributed throughout the society and among many adepts on the basis of personal capacity or potentiality.

Indeed, African pre-colonial discourses on the 'human' allowed for personal differentiation or singularity. It was believed that certain qualities lived in the individual from his or her birth; which he or she had no need for 'magic' to arouse although there was always the indispensable need for magical rites to conserve these. Personal abilities could be augmented, conserved and actualised within the person, making that person a 'real person', recognised as such by the community. Each individual person's power was itself a composition. 
That some of these old tropes might still be at work in current controversies on wealth and property should not be entirely excluded. But that wealth, poverty and property have become essential to the self-understanding of South African society after liberation should also be read against a long history of black dispossession. In the new phase of 'frontier accumulation' made possible by the 1994 negotiated settlement, they have become the new idioms for political and normative arguments about what should be the proper relation of people to things; what should be the proper relation of people to each other with respect to things; how much property is enough for one person and how much is too much; how much enjoyment is justifiable especially for the opulent in an environment where hunger and debasement are all too real for many. It is this tension between what looks like an unstoppable logic of unproductive excess on the one hand and on the other, a logic of scarcity and depletion that is turning wealth and property into dramatic sites of contestation.

Wealth and property also operate as means of regulating access to resources that are scarce for some and plentiful for others. They are the main means by which life chances are assigned to different kinds of persons at a time when pockets of wealth and privilege are proving hard not only to account for and even less so to control, but also hard to subject to some form of accountability and redistribution. Furthermore, as Arjun Appadurai observes, the life of the poor has become a strenuous effort to produce, if not a sense of stability, then something like permanence in the face of the temporariness or volatility of almost all the arrangements of social existence. Indeed, one of the most brutal effects of neo-liberalism in South Africa has been the generalisation and radicalisation of a condition of temporariness for the poor. For many people, the struggle to be alive has taken the form of a struggle against the constant corrosion of the present, both by change and by uncertainty.

In order to reanimate the idea of 'the human' in contemporary South African politics and culture, there is therefore no escape from the need to reflect on the thoroughly political and historical character of wealth and property and the extent to which wealth and property have come to be linked with bodily life. If what distinguishes the South African experiment from other such experiments elsewhere in the world is the attempt to establish a new relationship between law and life while equating democracy and the political itself with the ethical and the just, then we have to ask under what conditions can this project of human mutuality result in a broader and more ethical commensality.

\section{Race and difference}

Another major challenge to any re-imagination of 'the human' in contemporary conditions is race. South Africa's democracy asserts the equality of all human beings and seeks to derive powers of government from the consent of the governed. Yet, this is a democracy founded on deep and entrenched forms of racial dispossession and inequality inherited from a past of racial brutality. The country's entire modern history is spliced around and fractured by the question of the relationship between its parts - whether they should exist alone, separate, or whether they should exist with other parts, together. This dialectic between with and without played itself 
out dramatically during the years of apartheid. It is being played out again, in no less dramatic fashion, between those with and those without property. The end of apartheid has not resolved the old question of difference. It has simply shifted the terms of the difference and of the dispute. In order to make decisions about issues of distribution and sharing in such a way that the social body does not turn against itself, the new democracy must find an adequate language of claims, liabilities, or debts - a proper language to keep putting forth the demand for justice, compensation, redress, restitution and reparation our history places before us.

To these challenges must be added yet another, represented by the stranger in our midst. In contemporary South Africa, 'undocumented' or 'illegal migrants' are people whose fundamental rights are in jeopardy. They are halfheartedly protected in the confines of the national territory where they reside. Post-apartheid South Africa has inherited a long tradition of a 'politics of separation'. For centuries, this country was ruled according to that principle - to physically separate itself from all kinds of 'other humans'; the refusal to share the same space with these 'other humans' or to live with them.

Worldwide, a global regime of walling is fast contributing to the manufacturing of entire categories of unwanted people of which the illegal migrant, the undocumented worker, and more and more the refugee and the asylum seeker, are the prototypes. This global regime is characterised by the differential treatment of individuals, groups or communities with respect to movement or circulation. This differential treatment raises, at a deeper level, questions about the way in which the 'quality of being human' as such is instituted in a globalised society; the way in which the quality of being human becomes once again categorised and hierarchised so that its selective reproduction can be controlled; so that some human beings can be hunted by the police of certain States and their freedom of circulation subjected to massive controls and restrictions.

The gigantic inequality with regard to the right of circulation and the mobility of persons nowadays constitutes a transnational social relationship in and of itself. It is fuelled by an anthropological crisis of the category of 'the human person' as a 'universal' category. It is also at the roots of new, global forms of racialisation, in the name of security.

\section{The category of the future}

The 'human' is another name for the future. In the political history of South Africa, the future has always been the term by which the struggle to produce a meaningful life has been named. What gave the category of the future its power was the hope that we might bring into being - as a concrete social possibility - a radically different temporal experience; that a systemic transformation in the logic of our social life and in the logic of our being-in-common as human beings might happen as a result of historical praxis.

For many, the process of producing life now tends to take the form of a struggle to make it from today to tomorrow, and to cross the boundary from today to tomorrow 
can no longer be taken for granted. In fact, it has become eminently hazardous, risky. To be alive is to constantly be at risk; to constantly have to take risks because the penalty for not taking risks is to not be able to make it from today to tomorrow. As the possibility of the Event recedes, South Africa is faced with the 'liquid' character both of the present and of the future, their dizziness, their mirage-like qualities, the weakness in our grip on the future.

We should wonder whether there is a direct relationship between the liquidity of the present and the overwhelming feeling of the elusiveness of the future - and therefore the apparent foreclosure of any plausible form of radical politics. In fact, many live as if the present, democracy, the law and the Constitution, had unexpectedly betrayed them. What consequences this feeling of betrayal entails for our imagination of the future is far from having been properly assessed. On the one hand, it manifests itself via the constant re-apparition of the past in almost every single act that aims at bringing a different future into being. On the other hand, it is as if for many people too much has changed and yet not enough has changed. There is a feeling (especially among the poor) that they are now not merely deprived of wealth and power, but even of life possibilities as such. Throughout the entire society, there is a widely shared belief that in order to further one's claims, it might be better and more efficient to resort to violence rather than to invoke the law. This accelerated turn to an everyday politics of expediency rather than a demanding, disciplined politics of principle is fuelled by the inability to open freedom onto the un-chartered territories of the future.

Many have the feeling that they might never really fulfil their lives; that their lives will always be somewhat truncated; that these lives will never achieve the status of lives that are accounted for, inhabited as they are by a 'ghost'. Beyond the repetition of dead paradigms, any new form of radical politics will have to deal with this ghost in life, the pain of disappointment and the sharp experience of defeat, of palpable powerlessness and dashed hopes.

The period after apartheid is a period of 'reconstruction' and 'redesign'. The challenge ahead is nothing less than the re-foundation of democracy as a community of life. The end of apartheid, just as decolonisation in other parts of Africa, has opened the door to internal partition. It has not entirely resolved the question of difference; of how to make decisions about issues of redistribution and sharing. Yet, the need to experiment with new forms of ethical relations has never been as acute as now. The question this country is therefore facing today as yesterday is under what conditions can South Africa re-imagine democracy not only as a form of human mutuality and freedom, but also as a community of life. In order to confront the ghost in the life of so many, the concepts of 'the human', or of 'humanism', inherited from the West will not suffice. We will have to take seriously the anthropological embeddedness of such terms in long histories of 'the human' as waste. 